\title{
Infância nos caminhos da Psicologia: representações de infância psicologizada na revista Pais \& Filhos (1968-
}

1989)

Childhood in the paths of psychology: representations of psychological childhood in the Pais \& Filhos magazine (1968-1989) Liana PEREIRA Borba dos SANTOS (iDa

aProfessora no Colégio Pedro II. Doutora em Educação, e-mail: lianaborba@gmail.com. Orcid: http://orcid.org/0000-0002-0617-4998 


\title{
INFÂNCIA NOS CAMINHOS DA PSICOLOGIA: REPRESENTAÇÕES DE INFÂNCIA PSICOLOGIZADA NA REVISTA PAIS \& FILHOS (1968-1989)
}

\section{RESUMO}

Este estudo, de caráter histórico e documental, visa compreender de que forma a revista mensal Pais \& Filhos contribuiu para a produção e a divulgação de representações de uma dimensão de infância psicologizada na sociedade brasileira no período de 1968 a 1989, segundo perspectiva que tinha na Psicologia do Desenvolvimento e na Psicanálise suas bases científicas por excelência. $\mathrm{O}$ estudo das representações remete às práticas socioculturais que possibilitam, circunscrevem e determinam experiências de infância em um contexto histórico (CHARTIER, 2002; KUHLMANN JR.; FERNANDES, 2004). Em Pais \& Filhos, constatou-se a presença da Psicologia do Desenvolvimento como discurso canônico sobre a infância, por meio de matérias, seções fixas e testes que apresentavam o processo de crescimento da criança em bases cronológicas. $\mathrm{O}$ tema da sexualidade infantil também se destacou pela divulgação de modos de "fazer falar o sexo" (FOUCAULT, 2009), exemplificado pela frequência do discurso especializado que visava explicar o desenvolvimento afetivo e sexual das crianças tendo os estudos de Freud, Klein e Winnicott como referências predominantes. Pais \& Filhos atuou como espaço pedagógico de formação dos pais-leitores, servindo de guia aparentemente confiável e especializado para a explicação dos comportamentos infantis. Espera-se, assim, que este estudo contribua para o campo de produção científica que tem as representações relativas à infância e à sua educação como foco, assim como para o campo de estudos da História da Educação que tem a imprensa periódica de ampla circulação como fonte privilegiada de pesquisa.

Palavras-chave: Revista Pais \& Filhos. Impressos Educativos. Representações de infância. Psicologia. Pais leitores.

\section{CHILDHOOD IN THE PATHS OF PSYCHOLOGY: REPRESENTATIONS OF PSYCHOLOGICAL CHILDHOOD IN THE PAIS \& FILHOS MAGAZINE} (1968-1989)

\begin{abstract}
The study aims to understand how the monthly magazine Pais \& Filhos contributed to the production and dissemination of representations of a psychologized childhood dimension in Brazilian society from 1968 to 1989, according to perspective based in Developmental Psychology and in Psychoanalysis. The study of representations refers to the sociocultural practices that enable, circumscribe and determine childhood experiences in a historical context (CHARTIER, 2002; KUHLMANN JR.; FERNANDES, 2004). In Pais \& Filhos, we found the presence of Developmental Psychology as a canonical discourse about childhood, through subjects, fixed sections and tests that presented the process of child growth on chronological basis. The theme of child sexuality was also highlighted by the dissemination of ways to "make sex talk" (FOUCAULT, 2009), exemplified by the frequency of specialized discourse that aimed to explain the affective and sexual development of children, having the studies of Freud,


Infância nos caminhos da Psicologia: representações de infância psicologizada na revista Pais \& Filhos (19681989)

Klein and Winnicott as predominant references. Pais \& Filhos acted as a pedagogical training ground for parent-readers, serving as a seemingly reliable and expert guide to explaining child behavior. On hope to contribute to the field of scientific production that has representations related to childhood and its education as a focus, as well as to the studies of the History of Education that has the periodic press as source and object of research.

Key-words: Pais \& Filhos Magazine. Educational Press. Representations of childhood. Psychology. Parents readers.

\section{LA INFANCIA EN LOS CAMINOS DE LA PSICOLOGÍA: REPRESENTACIONES DE LA INFANCIA PSICOLÓGICA EN LA REVISTA PAIS \& FILHOS (1968-1989)}

\section{RESUMEN}

Este estudio histórico y documental tiene como objetivo comprender cómo la revista mensual Pais \& Filhos contribuyó a la producción y difusión de representaciones de una dimensión infantil psicologizada en la sociedad brasileña desde 1968 hasta 1989, de acuerdo con la perspectiva que tuvo en Psicología del desarrollo y en psicoanálisis sus bases científicas por excelencia. El estudio de las representaciones se refiere a las prácticas socioculturales que permiten, circunscriben y determinan las experiencias de la infancia en un contexto histórico (CHARTIER, 2002; KUHLMANN JR.; FERNANDES, 2004). En Pais \& Filhos, encontramos la presencia de la psicología del desarrollo como un discurso canónico sobre la infancia, a través de temas, secciones fijas que presentaron el proceso de crecimiento infantil en forma cronológica. El tema de la sexualidad infantil también se destacó por la difusión de formas de "hacer hablar de sexo" (FOUCAULT, 2009), ejemplificada por la frecuencia del discurso especializado que tenía como objetivo explicar el desarrollo afectivo y sexual de los niños, teniendo los estudios de Freud, Klein y Winnicott como referencias predominantes. Pais \& Filhos actuó como un campo de entrenamiento pedagógico para padres-lectores, sirviendo como una guía aparentemente confiable y experta para explicar el comportamiento del niño. Por lo tanto, se espera que este estudio contribuya al campo de la producción científica que tiene como objetivo las representaciones relacionadas con la infancia y su educación, así como a los estudios de la Historia de la Educación, que tiene una amplia circulación en la prensa periódica.

Palabras-clave: Revista Pais \& Filhos. Impresos educativos, Representaciones de la infancia. Psicologia. Padres lectores,

\section{Introdução}

Rev. Caminhos da Educação: diálogos, culturas e diversidades, Teresina, v. 2, n. 1, p. 106-126, jan./abr. 2020 
Este estudo, de caráter histórico e documental, visa compreender de que forma a revista mensal Pais \& Filhos contribuiu para a produção e a divulgação de representações de uma dimensão de infância psicologizada na sociedade brasileira no período de 1968 a 1989, perspectiva que tinha na Psicologia do Desenvolvimento e na Psicanálise suas bases científicas por excelência (SANTOS, 2018).

Lançada em 1968 pela Bloch Editores S.A., Pais \& Filhos tem como proposta editorial discutir aspectos relacionados à saúde, à educação e ao comportamento das crianças e de suas respectivas famílias. Em circulação, o periódico é atualmente produzido pela Editora Manchete, tratando-se de uma das publicações de maior longevidade do mercado brasileiro.

A consulta ao acervo de Pais \& Filhos foi realizada na Fundação Biblioteca Nacional, localizada na cidade do Rio de Janeiro. Sua pertinência para a pesquisa em História da Educação é justificada por seu papel divulgador de discursos acerca da educação das crianças, dirigidas às famílias, o que vai ao encontro das reflexões históricas e culturais que consideram a imprensa periódica como um constructo social (NÓVOA, 2002).

No caso específico do levantamento e análise das representações de infância, considera-se a importância de uma contextualização histórica, já que o estudo das representações remete às práticas socioculturais que possibilitam, circunscrevem e determinam experiências de infância (CHARTIER, 2002). A visada histórica à concepção de infância se apresenta, então, como possibilidade de aferição de um sentido histórico e político para o presente (PEREIRA, 2002).

Como discurso histórico, a significação da infância está consignada a contextos de natureza econômica, social, política, cultural, demográfica, pedagógica etc., tratandose, ainda, de representações dos adultos que agregam o sentido de uma infância de longa duração, com subdivisão em fases mais específicas (KUHLMANN JR.; FERNANDES, 2004). A análise das representações da infância permite, nessa perspectiva analítica, a sua compreensão como objeto histórico plural e não como uma entidade ontológica singular.

Não custa lembrar que os diversos ramos disciplinares (Historiografia, Sociologia, Psicologia, Direito, Literatura e Pedagogia, por exemplo) disputam e negociam representações sobre a infância, na medida em que constituem discursos e 
Infância nos caminhos da Psicologia: representações de infância psicologizada na revista Pais \& Filhos (19681989)

competências narrativas em seus respectivos campos. Em Pais \& Filhos, especificamente, constatou-se que a Psicologia frequentemente ocupou espaço discursivo acerca da infância, exemplificado pela presença do slogan "Saúde e psicologia para toda a família" nas edições de maio de 1984 até janeiro de 1986.

Nesse contexto, que discursos foram divulgados e produzidos pela revista, visando à consolidação de determinada dimensão de infância? Quais campos de saber foram colocados em cena a fim de legitimar tais representações do mundo social? O exame da revista fornece pistas de que o saber psicológico atuou como fundamento importante nas representações de infância ali divulgadas.

\title{
Caminhos do desenvolvimento infantil
}

\begin{abstract}
Para onde caminha a infância? Há oitenta e cinco anos comemorava-se a entrada de um novo século, aquele que seria dedicado à criança. Mil planos foram feitos na época. E o objetivo maior de todos eles era garantir aos pequeninos o direito de se tornarem adultos normais e saudáveis. O que assistimos hoje, no entanto, é uma certa falência do famoso projeto. Um quarto das crianças de todo mundo não se beneficiou dos avanços tecnológicos da Medicina. Sobrevivem precariamente, sofrendo a falta de saúde, educação, higiene, alguns de seus direitos de mais legitimos. Agora, que se aproxima uma nova virada do século, é hora de refletir sobre nossos próprios filhos e, mais longe ainda, sobre a infância do Futuro, para que ela seja realmente feliz e digna de ser vivida. Como nós desejamos! (REVISTA PAIS \& FILHOS, n. 4, dez. 1985, p. 4, grifo nosso)
\end{abstract}

A redatora Amelia Gonzalez apontou o início do século XX como importante marco na preocupação social em relação à infância. Afirmou que, naquele período, "mil planos foram feitos" em prol do projeto normatizador da sociedade, que visava à formação de adultos saudáveis e normais. Como expressa a articulista, tal intento não alcançou a totalidade da população infantil, tampouco contemplou todas as classes sociais, deixando de atender uma grande gama de crianças em seus direitos básicos de proteção, saúde, higiene e educação.

Rev. Caminhos da Educação: diálogos, culturas e diversidades, Teresina, v. 2, n. 1, p. 106-126, jan./abr. 2020 
No contexto brasileiro, tal situação não é específica do século XX, identificada nas pesquisas acerca da história das crianças no Brasil desde o período colonial (DEL PRIORE, 1999). Todavia, ganha relevo a permanência da questão no discurso exposto em Pais \& Filhos e a expectativa de superação nos anos 2000. O artigo publicado em 1985 também exemplifica o modo pelo qual Pais \& Filhos produziu enunciados visando não só os seus leitores, e sim a sociedade como um todo.

Essa discussão revela, ainda, a forma por meio da qual os discursos divulgados em Pais \& Filhos se articularam ao contexto científico mais amplo em torno da infância, reconhecidamente alvo de campos de saberes como Medicina, em seus ramos específicos de Higiene, Pediatria e Puericultura; Psicologia do Desenvolvimento e Psicanálise; e Pedagogia, em uma abordagem "científica".

Importa atentar para o fato de que a Psicologia somente alcançou o estatuto de ciência autônoma no último quartel do século XIX. No Brasil, por seu tempo, a história do desenvolvimento deste campo indica que ele permaneceu ligado a outras áreas de saber até o século XX. Contudo, a preocupação com os fenômenos psicológicos fez-se presente desde os tempos da colônia, aparecendo em obras escritas nas diferentes áreas do saber e, mais tarde, durante o século XIX, em produções advindas de instituições como faculdades de Medicina, hospícios, escolas e seminários (ANTUNES, 2014, p. 12). Mitsuko Antunes assinalou que foram recorrentes as preocupações com a criança e seu processo educativo, relacionadas aos temas da formação da personalidade; do desenvolvimento da criança; do controle e manipulação do comportamento; da aprendizagem; da influência dos pais etc.

Merece destaque a dimensão histórica e cultural da idade como orientadora do desenvolvimento humano, constatada em Pais \& Filhos na segmentação de seções pela idade dos filhos, assim como em trechos como o seguinte, integrante da matéria intitulada "Meus primeiros amiguinhos":

1 ano - Ele se reconhece como pessoa num outro neném, fica encantado ao ver alguém do seu tamanho, com olhos, nariz, boca e movimentos. Mas, na hora de brincar, o amiguinho é indiferente. Prefere fazer sozinho suas pesquisas.

2 anos - É a idade da imitação. 0 amigo não é ainda um companheiro de brincadeiras, mas alguém que faz alguma coisa para ela acompanhar. Aparentemente, brincam juntos; na realidade, apenas fazem a mesma coisa, lado a lado.

3 anos - Começa a competição. Ele quer o brinquedo do outro, sempre mais bonito que o seu. E, enquanto compete, vai aprendendo a traçar seus limites, ver o amiguinho como uma pessoa à parte: é ele, o brinquedo é dele. 
Infância nos caminhos da Psicologia: representações de infância psicologizada na revista Pais \& Filhos (19681989)

4 anos - Agora há verdadeiramente uma intenção de partilhar as brincadeiras. Os brinquedos podem ser "emprestados" e brincar com o amiguinho já não gera uma competição. 0 "outro" passa a ser fonte de novas brincadeiras e diversões.

5 anos - Sem que a criança percebesse, criou seus laços de verdadeira amizade. 0 companheiro escolhido é sempre o mais querido, com quem pode planejar mil coisas e dividir suas aventuras emoções. Ela já sente o prazer do "nós" (REVISTA PAIS \& FILHOS, n. 5, jan. 1973, p. 10-11).

O texto descreveu aos pais leitores etapas de socialização correspondentes ao desenvolvimento etário da criança. Ela partiria de uma situação de indiferença "ao amiguinho", passaria pelo brincar lado-a-lado, sem brincar junto, e atingiria o ápice aos cinco anos, quando já seria capaz de sentir prazer na parceria e em dividir aventuras.

$\mathrm{O}$ processo de desenvolvimento correspondente às idades descritas no excerto não foi claramente atribuído a uma abordagem teórica pela publicação, até porque se tratava claramente de um público previsto leigo, não especializado no assunto. Entretanto, identificou-se uma proximidade com os seguintes períodos ou estágios de desenvolvimento propostos por Jean Piaget (1896-1980), a saber: a) Sensório-motor (02 anos) e b) intuitivo ou pré-operatório (2-7 anos).

A presença da Psicologia do Desenvolvimento mostra-se, pois, como discurso canônico sobre a infância nas páginas de Pais \& Filhos, com vistas a se legitimar como a ciência que descreve e explica como é que, a partir de um equipamento inicial, o sujeito vai sofrendo uma série de transformações decorrentes de sua maturação (fisiológica, neurológica e psicológica) que, em contato com o meio físico e social, levam à emergência de determinados comportamentos (RAPPAPORT; FIORI, DAVIS, 1981).

Em uma perspectiva mais ampla da constituição de campos de saberes acerca da infância, o poder de legitimação de uma verdade sobre o desenvolvimento humano faz uso de estratégias de controle dos meios de comunicação e da produção de sentido por meio de discursos ali proferidos. Especificamente em Pais \& Filhos, a publicação de testes a serem respondidos pelos leitores exemplifica uma estratégia de legitimação de determinados marcos de desenvolvimento infantil e, ao mesmo tempo, potencializa 
mudanças no comportamento dos pais a partir de uma atividade lúdica. O trecho do teste “Agora você mesma vai testar seu bebê” fornece indícios dessa afirmação.

\begin{abstract}
Observar o desenvolvimento de um filho é uma das experiências mais gratificantes da maternidade. O primeiro sorriso, as tentativas de ficar sentado, os passinhos incertos e trôpegos, a palavra mamãe sendo pronunciada pela primeira vez... São conquistas que deslumbram os pais. E não é para menos. Afinal, estes são os primeiros patamares de uma vida inteira. No entanto, lado a lado com o prazer de estar vendo o pequenino crescer, existe também, em cada um de nós, o desejo de saber se ele está acompanhando as outras crianças, se seu desenvolvimento está normal, enfim se ele é uma pessoa saudável. Para tirar as dúvidas, faça este teste e veja como seu bebê está progredindo. Durante os primeiros 14 meses de vida do bebê, o desenvolvimento motor e intelectual é muito acelerado. É um período de várias conquistas: andar, falar, comer alimentos sólidos e se relacionar com as outras pessoas, além da mãe, são algumas das mais significativas. Apesar de sabermos que cada criança tem seu ritmo próprio e que suas características devem ser respeitadas, não há mãe que resista a verificar, através de testes, se o filho está dentro da média no que se refere ao desenvolvimento de suas habilidades (REVISTA PAIS \& FILHOS, n. 12, ago. 1985, p. 7-8)
\end{abstract}

De acordo com a publicação, o teste foi elaborado pela psicóloga alemã Irene Burtchen e contou com a participação de pais de diversos países europeus. Destaca-se a utilização de conteúdo já publicado na revista alemã Eltern, constatada na indicação "Fotos e reportagem Eltern", aspecto que exemplifica uma perspectiva transnacional dos discursos acerca infância veiculados em revistas parentais (SANTOS, 2019).

A despeito das diferenças culturais sinalizadas no próprio texto, prevaleceu o objetivo de validar "comportamentos esperados nas diversas fases de evolução". O aspecto afetivo desse tipo de proposta é evidente, já que o teste foi apresentado como expressão da preocupação comum às mães de verificar "se o filho está dentro da média no que se refere ao desenvolvimento de suas habilidades". Além disso, ele prometia oferecer aos pais a oportunidade de "testar e julgar com segurança o desenvolvimento do filho de 0 a 14 meses".

A segmentação etária merece ser problematizada, na medida em que corresponde a uma forma historicamente construída de explicar o desenvolvimento humano. Deve-se atentar para a dimensão cultural de tais marcos e considerar sua articulação às instituições que constroem e utilizam o tempo transcorrido desde o nascimento como medida de desenvolvimento:

Com o surgimento da industrialização e os esforços para sistematizar serviços como educação e atendimento médico, a idade tornou-se uma medida de desenvolvimento e um critério de classificação das pessoas. Instituições especializadas foram projetadas em Rev. Caminhos da Educação: diálogos, culturas e diversidades, Teresina, v. 2, n. 1, p. 106-126, jan./abr. 2020 
Infância nos caminhos da Psicologia: representações de infância psicologizada na revista Pais \& Filhos (19681989)

função de grupos etários. A Psicologia do Desenvolvimento e a Pediatria tiveram início nessa época, junto com as instituições para idosos e as escolas organizadas por idades (ROGOFF, 2005, p. 19).

O lugar ocupado pela Psicologia do Desenvolvimento como campo de saber que autoriza e legitima a construção de teorias e conceitos sobre os aspectos evolutivos da infầncia (cognitivos, afetivo-emocionais, psicomotores, sociais etc.) também foi estudado para Solange Jobim e Silva.

Para ela, a Psicologia do Desenvolvimento corresponde à instituição social com estrutura profissional e presença pública, que atua na segmentação, classificação, ordenamento e coordenação do crescimento humano, colaborando para engendrar um discurso desenvolvimentista (JOBIM E SILVA, 2007, p. 40).

A autora observa ainda que, ao mesmo tempo em que busca compreender fatos pouco conhecidos do desenvolvimento humano, a Psicologia do Desenvolvimento colabora para a estruturação de uma dada experiência de infância, determinando ideais de comportamentos cognitivos, afetivos, psicomotores e sociais.

É digna de nota a dimensão sociocultural dos discursos divulgados na revista. Pretendia-se interferir na cultura familiar e modificar os comportamentos afetivos dos pais-leitores, afirmação exemplificada pela matéria "Quando brincar significa desarrumar", assinada por Pamela Nunes, com consultoria da psicóloga clínica Marcia Nunes e ilustrada com fotos de Eltern.

Ele começou a engatinhar. Para os pais, isto significa uma verdadeira revolução no lar. A casa, até então organizada, transforma-se em um amontoado de brinquedos e os cristais da mamãe estão sempre sob ameaça. Mas esta é apenas uma fase, característica da primeira infância que dura, em geral, três anos. E se você pensar que este transtorno é fundamental para o desenvolvimento da personalidade da criança, tudo ficará mais fácil. Nesta reportagem, algumas informações sobre esse período da vida do seu filho, além de dicas para você atravessar com tranquilidade esta fase que, convenhamos, não é tão caótica assim (REVISTA PAIS \& FILHOS, n. 12, ago. 1981, p. 36).

A matéria elucida o investimento discursivo de consagrar a atividade de brincar e a livre exploração do espaço como comportamentos típicos da natureza infantil e 
correspondentes a determinados marcos de idade. Ter uma criança em casa exigiria, neste sentido, uma mudança na própria atuação dos pais, culminando em uma "revolução no lar".

Essa matéria foi republicada em dezembro de 1985, com o título "Revolução na casa: o bebê exige liberdade". Pamela Nunes e a consultora Marcia Antunes permaneceram identificadas no artigo de 1985. Observaram-se pequenas mudanças na introdução, nas fotografias utilizadas e na supressão de um parágrafo, mantendo-se o longo trecho a seguir:

É por volta dos nove meses de vida que a criança começa a engatinhar. A partir daí, o mundo, que para ela era restrito ao berço ou a um cercado, ganha nova dimensão. Ela agora tem um espaço bem maior para circular, onde tudo é novidade. A criança quer explorar este espaço e vai fazê-lo, ainda que isto signifique algumas dores de cabeça dos pais que, não raro, ficam inconformados com o verdadeiro caos, que fatalmente, instala-se em suas casas, outrora tão arrumadinhas. Nesta época, também o pequenino já é capaz de fazer diversas outras coisas como, por exemplo, beber água sozinho, segurando ele próprio o copo. Não se admire, no entanto, se o seu bebê achar fascinante a ideia de atirá-lo longe com água e tudo. Ele provavelmente vai fazer a mesma coisa com todos os objetos que estiverem ao seu alcance. Logo depois, por volta dos 10 meses, seu filho começa a querer andar. Numa primeira fase, vai tentar os primeiros passos segurando nos móveis da casa. Mais um problema para as mamães muito ansiosas. 0 jeito é guardar um tempo aquela porcelana inglesa tão valiosa, os cristais da vovó ou o vaso chinês e (que remédio!) aguardar pacientemente que esta fase seja ultrapassada. Já um pouquinho maior, lá pelos dois anos de idade, a criança descobre o lápis e o papel e transforma-se num artista precoce. Perfeito que seja assim, é importante para o seu desenvolvimento motor. Mas acontece que nem sempre uma simples folhinha lhe basta. Ela precisa expandir-se e é bem provável que prefira para os seus riscos e rabiscos justamente aquela parede branca, recém-pintada. Com tranquilidade e um paninho embebido de água ou solvente, o problema ficará resolvido (REVISTA PAIS \& FILHOS, n. 12, ago. 1981, p. 38; Id., n.4, dez. 1985, p. 17).

O texto comum às duas edições exemplificou comportamentos de crianças no decorrer do primeiro ano de vida e apontou ações que os pais poderiam tomar a fim de evitar riscos às crianças, sem privá-las da liberdade de movimentos. Todavia, convém secundarizar o aspecto biológico do desenvolvimento, atentando-se para a dimensão sociocultural desse tipo de discurso, que marca o pertencimento das crianças em questão às camadas médias e altas da sociedade. Estas teriam a possibilidade de habitar casas com certo espaço de locomoção, com paredes "brancas e recém-pintadas" e cuja decoração poderia contar com "vasos chineses" ou "porcelanas inglesas tão valiosas".

No âmbito dessas representações de desenvolvimento infantil, excluem-se claramente as crianças que habitavam apenas um cômodo, com paredes de madeira, tijolo exposto, barro ou até mesmo papelão, que provavelmente não tinham acesso a 
Infância nos caminhos da Psicologia: representações de infância psicologizada na revista Pais \& Filhos (19681989)

materiais para expandir seus movimentos e riscar e rabiscar paredes com lápis e giz de cera.

Já na epígrafe do artigo, a questão da liberdade ganhou destaque, citando-se Alexander S. Neill, importante defensor da educação libertária e reconhecido internacionalmente pelo trabalho desenvolvido na escola inglesa Sumerhill: "No lar disciplinado, a criança não tem direitos. No lar fraco, ela terá todos os direitos. No lar sadio, ela e os adultos têm direitos iguais" (REVISTA PAIS \& FILHOS, n. 12, ago. 1981, p. 38; Id., n.4, dez. 1985, p. 17).

Chamou a atenção, ainda, a veiculação de uma segunda citação direta ao autor na conclusão das matérias:

E como diz A. S. Neill, no livro Liberdade sem Medo: 'A criança modelada, condicionada, disciplinada, reprimida, a criança sem liberdade, cujo nome é Legião, vive em todos os cantos do mundo. Vive em nossa cidade, mesmo do outro lado da rua. Senta-se em uma carteira monótona de monótona escola, e mais tarde senta-se em uma escrivaninha ainda mais monótona de escritório. É dócil, disposta a obedecer à autoridade, medrosa da crítica e quase fanática em seu desejo de ser normal, convencional e correta' (Ibid., p. 40; Ibid., p. 19).

Em acréscimo, ressalta-se que entre os princípios da filosofia norteadora de sua pedagogia, estavam: a) o direito à liberdade pelas crianças; b) a importância da autoregulação pelo grupo de crianças; c) a preocupação com a licenciosidade, causada pelo excesso de liberdade e caracterizada pela desconsideração dos limites alheios; d) o entendimento de que a repressão sexual é um dos males da humanidade, em clara correspondência com a teoria freudiana. A despeito de sua importância no campo da educação, interessou, nesse ponto, a apropriação que Pais \& Filhos faz da teoria de Neill em prol da disseminação de uma representação de infância caracterizada por um comportamento explorador e livre.

\section{Infância e sexualidade, eis a questão}


O tema da sexualidade infantil ganhou relevo no movimento de divulgação de modos de agir indicados às mães e pais leitores do periódico, conforme aspectos observados em várias edições da publicação. Ocorreu a frequência do discurso especializado que visava explicar o desenvolvimento afetivo e sexual das crianças tendo os estudos de Freud, Klein e Winnicott como referências predominantes. Que indícios, afinal, este investimento editorial fornece a respeito de um tipo de representação de infầncia e de sua sexualidade em circulação no contexto pesquisado?

No caso específico da sexualidade da criança, Foucault afirma que a sociedade moderna experimentou um processo de institucionalização dos discursos sobre a infância, em que a sexualidade assumiu papel de destaque como "um dos instrumentos de troca que permitiram deslocar a criança do meio da sua família para o espaço institucionalizado e normalizado da educação" (FOUCAULT, 2001, p. 226). Educação que se constrói também por meio de veículos culturais como as revistas.

No âmbito de sua investigação, Foucault assinalou que a sexualidade da criança passou por um processo de pedagogização (FOUCAULT, 2009. p. 114), que diz respeito à afirmação de que quase todas as crianças se dedicam ou são suscetíveis às práticas sexuais. Tal conduta, segunda sua análise, caracteriza-se por certa ambiguidade, pois vê a sexualidade da criança como "natural" e "contra a natureza", trazendo consigo perigos físicos e morais, coletivos e individuais.

Os discursos a respeito da sexualidade infantil integram um movimento histórico identificado por Foucault como a "incitação aos discursos". Trata-se, afinal, do contexto de explosão discursiva pautada em um maior controle do vocabulário e de certas enunciações. A multiplicação dos discursos sobre o sexo atua no próprio campo do exercício do poder, pela incitação institucional a falar cada vez mais e, por outro lado, pela obstinação das instâncias de poder que visam ouvir e fazer falar.

Pais \& Filhos pode ser, então, considerada uma instância de enunciação de discursos sobre a sexualidade, cuja obstinação em tratar do assunto aparece na leitura de artigos cujo conteúdo abordava diretamente a sexualidade das crianças:

Quadro 1- Seleção de artigos com a temática da sexualidade publicados da revista Pais \& Filhos (1968 a 1989)

\begin{tabular}{|c|c|c|c|c|l|}
\hline Ano & N. & Mês & Título & Autor(a) & \multicolumn{1}{c|}{ Consultor(a) } \\
\hline 1969 & 5 & Janeiro & $\begin{array}{c}\text { Vovó ainda acredita em } \\
\text { cegonha }\end{array}$ & Solange Sena & $\begin{array}{l}\text { Rossely S. Matheus Peres, } \\
\text { formada pelo Instituto de } \\
\text { Psicologia da Universidade } \\
\text { de Paris }\end{array}$ \\
\hline
\end{tabular}

Rev. Caminhos da Educação: diálogos, culturas e diversidades, Teresina, v. 2, n. 1, p. 106-126, jan./abr. 2020 
Infância nos caminhos da Psicologia: representações de infância psicologizada na revista Pais \& Filhos (19681989)

\begin{tabular}{|c|c|c|c|c|c|}
\hline 1969 & 5 & Janeiro & $\begin{array}{l}\text { Veste essa roupa, } \\
\text { menina }\end{array}$ & Sheila Mazzolenis & $\begin{array}{l}\text { Amaryllis Schivinger, chefe } \\
\text { do Serviço de Psicologia do } \\
\text { Departamento } \\
\text { Assistência do Menor da } \\
\text { Secretaria de Serviços } \\
\text { Sociais do Estado da } \\
\text { Guanabara; Dr. Eliézer } \\
\text { Rosa, juiz da } 8^{\text {a Vara }} \\
\text { Criminal (Rio) }\end{array}$ \\
\hline 1971 & 1 & Setembro & $\begin{array}{c}\text { O que seu filho tem a } \\
\text { ver com Melanie Klein }\end{array}$ & Paulo Sternick & $\begin{array}{l}\text { Dr. Fábio Leite Lobo, } \\
\text { diretor do Instituto de } \\
\text { Psicanálise da Sociedade } \\
\text { Psicanalítica do Rio de } \\
\text { Janeiro; Maria Imelde Farah, } \\
\text { psicanalista infantil e de } \\
\text { adultos, da equipe de Pais \& } \\
\text { Filhos. }\end{array}$ \\
\hline 1975 & 7 & Março & $\begin{array}{l}\mathrm{O} \text { universo sexual da } \\
\text { criança segundo Freud }\end{array}$ & Não consta informação & Não consta informação \\
\hline 1975 & 1 & Setembro & $\begin{array}{l}\text { A evolução sexual da } \\
\text { criança }\end{array}$ & Lúcia Etienne Romeu & Plínio Leite, psicólogo \\
\hline 1975 & 3 & Novembro & $\begin{array}{l}\text { Eles querem ter uma } \\
\text { conversinha com você. } \\
\text { Assunto: sexo }\end{array}$ & Leda Beck & 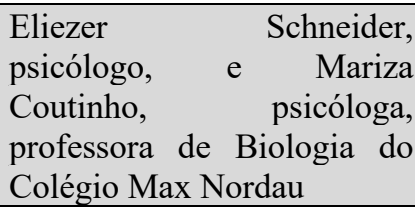 \\
\hline 1976 & 2 & Outubro & $\begin{array}{l}\text { Criança precisa saber. } \\
\text { Sexo não tem segredo }\end{array}$ & Não consta informação & Não consta informação \\
\hline 1978 & 7 & Março & Masturbação infantil & Liana Corrêa Cortes & $\begin{array}{l}\text { Glória Leal Garcia-Roza, } \\
\text { psicóloga clínica }\end{array}$ \\
\hline 1979 & 5 & Janeiro & Educação sexual & Liana Corrêa Fortes & $\begin{array}{l}\text { Mariza Coutinho, psicóloga } \\
\text { clínica }\end{array}$ \\
\hline 1979 & 12 & Agosto & $\begin{array}{l}\text { Meninos } \mathrm{x} \text { meninas: } \\
\text { como educar }\end{array}$ & Simone Fernandes & $\begin{array}{l}\text { Moema Toscano, socióloga, } \\
\text { professora de sociologia da } \\
\text { PUC/RJ; Mariza Coutinho, } \\
\text { psicóloga clínica }\end{array}$ \\
\hline 1981 & 6 & Fevereiro & $\begin{array}{l}\text { Suplemento Especial - } \\
\text { As teorias infantis sobre } \\
\text { sexo }\end{array}$ & $\begin{array}{l}\text { Daniel Albert } \\
\text { Waitzfelder, psicólogo }\end{array}$ & $\begin{array}{l}\text { Daniel Albert Waitzfelder, } \\
\text { psicólogo }\end{array}$ \\
\hline 1982 & 2 & Outubro & Violência Sexual & Bia Falbo & $\begin{array}{ll}\text { Carlos Alberto } & \text { Medina, } \\
\text { sociólogo, e } & \text { Cynthia } \\
\text { Ladvocat, psicóloga } & \\
\end{array}$ \\
\hline 1982 & 4 & Dezembro & $\begin{array}{l}\text { Com crescem o menino } \\
\text { e a menina }\end{array}$ & Bia Falbo & $\begin{array}{l}\text { Dr. Peter } \text { Lincornick, } \\
\text { pediatra, e Therezinha } \\
\text { Gonzaga Ferreira, diretora } \\
\text { do Centro Educacional } \\
\text { Anísio Teixeira }\end{array}$ \\
\hline 1984 & 9 & Maio & $\begin{array}{l}\text { A criança e os grandes } \\
\text { nomes da história - }\end{array}$ & Simone Fernandes & Não consta informação \\
\hline
\end{tabular}

Rev. Caminhos da Educação: diálogos, culturas e diversidades, Teresina, v. 2, n. 1, p. 106-126, 


\begin{tabular}{|c|c|c|c|c|c|}
\hline & & & Sigmund Freud & & \\
\hline 1984 & 12 & Agosto & $\begin{array}{l}\text { A criança e os grandes } \\
\text { nomes da história - } \\
\text { Melanie Klein }\end{array}$ & Simone Fernandes & Não consta informação \\
\hline 1985 & 12 & Agosto & $\begin{array}{l}\text { Masturbação infantil - } \\
\text { o prazer e descobrir o } \\
\text { próprio corpo }\end{array}$ & Fátima Regina Telles & $\begin{array}{l}\text { Dra. Sandra Felgueiras, } \\
\text { psicóloga clínica }\end{array}$ \\
\hline 1986 & 5 & Fevereiro & Identidade sexual & Cristina Dória & Olga Goldfeld, psicanalista \\
\hline
\end{tabular}

Quadro produzido pela autora.

Disposta no Quadro 1 em ordem cronológica, constatou-se que nos anos 1970 a temática da sexualidade infantil ocupou maior espaço na revista (oito matérias) se comparado ao volume de artigos divulgados nos anos 1980 (sete matérias). Observou-se a recorrência de alguns assuntos, como constituição da identidade sexual em meninos e meninas e a masturbação infantil.

A psicóloga clínica Mariza Coutinho foi a profissional que obteve maior recorrência na consultoria de artigos, com três participações. Os demais profissionais da listagem foram consultores de um artigo cada. Destacou-se, ainda, a participação de dois profissionais do campo da Sociologia (Moema Toscano e Carlos Alberto Medina), e daqueles ligados à Psiquiatria, Pediatria, Educação e Direito.

De um lado, Pais \& Filhos pretendeu prestar um serviço educativo à sociedade, informando as famílias a respeito do desenvolvimento sexual infantil. De outro, este investimento contribuiu para a divulgação de determinada representação de infância, ancorada em um discurso científico de viés psicológico e psicanalítico.

Verificou-se a recorrência do argumento de que o desenvolvimento sexual da criança transcorreria a partir de determinadas "fases", como na matéria intitulada "O universo sexual da criança segundo Freud":

A sexualidade, segundo Freud, se expressa na criança em fases distintas, nas quais o instinto sexual se localiza, sucessivamente, em diferentes zonas erógenas, que são partes da epiderme ou das mucosas onde o estímulo do prazer emite suas sensações. Como, na criança, este instinto consiste em fazer surgir a sensação pelo estímulo a esta ou àquela zona erógena, compreende-se o objetivo sexual infantil como o da gratificação [...] A primeira fase especificada por Freud foi a oral, em que a boca não representa apenas um meio de saciar a fome, mas uma constante fonte de prazer, desde a amamentação. A sucção, por si mesma, dá prazer ao bebê pela excitação da boca e dos lábios, também zona erógena. A segunda fase, denominada anal, está relacionada às excreções de urina e fezes, uma outra fonte de prazer para a criança. A terceira foi compreendida, então, como a genital, aquela que vai determinar, com maior propriedade, a futura vida sexual, dependendo das satisfações ou bloqueios registrados nesta fase (PAIS \& FILHOS, mar. 1975, n. 7, p. 78). 
Infância nos caminhos da Psicologia: representações de infância psicologizada na revista Pais \& Filhos (19681989)

O fragmento em questão atribui a Sigmund Freud (1856-1939) a postulação das respectivas fases de desenvolvimento sexual, a saber: oral, anal e genital. Contudo, como o autor descreve tais fases? O discurso veiculado em Pais \& Filhos corresponde a uma tradução exata da teoria psicanalítica? Que importância social e histórica teve a descoberta freudiana em relação à sexualidade da criança?

Não se pode negar que Freud é considerado o principal nome da Psicanálise. Como ilustra o texto "A criança e os grandes nomes da história", também em Pais \& Filhos Freud foi apresentado como pertencente ao grupo de intelectuais que contribuíram para a história da infância:

\begin{abstract}
Antes de Freud, mundo olhava as crianças como seres sem vida interior - no máximo, aprendizes de adulto. Ele precisou se debater contra o conservadorismo para provar que existe uma sexualidade infantil e que todas as nossas vivencias ficam registradas no inconsciente. Apesar de toda ousadia, o Pai da Psicanálise era, no entanto, um homem austero e pacato. Leu muito durante a infância e chegou à velhice com a sensação de isolamento comum aos gênios. Sua obra, até hoje, muito discutida, lançou inegavelmente, uma luz definitiva sobre a mente humana (REVISTA PAIS \& FILHOS, n. 9, maio 1984, p. 19).
\end{abstract}

A redatora Simone Fernandes apresenta Freud como um nome de destaque no contexto discursivo a respeito da criança e de sua educação, por ter provado "que existe uma sexualidade infantil e que todas as nossas vivências ficam registradas no inconsciente". Até os dias atuais, suas descobertas são de grande importância para romper com uma perspectiva que superestima uma dimensão racional de existência e desconsidera os afetos e emoções, que compõem uma espécie de "caixa preta" da psiquê humana.

Franco Cambi também se alinha a essa percepção ao afirmar que a pedagogia deve a Freud "uma redefinição da infância, uma descrição nova das relações interfamiliares, um papel central atribuído à emotividade e à afetividade" (CAMBI 2009, p. 585). Bernard Jolibert, por sua vez, atribui a Freud uma renovação no que diz respeito à teoria da infância e ao seu desenvolvimento, na medida em que para ele a infância consiste em um período determinante para a formação da pessoa. Assim, Rev. Caminhos da Educação: diálogos, culturas e diversidades, Teresina, v. 2, n. 1, p. 106-126, jan./abr. 2020 
Jolibert afirma como decisiva a influência de Freud sobre o debate educativo do século XX, pois "são raros os autores contemporâneos que tenham abordado a pedagogia sem fazer referência direta ou indireta a Freud" (JOLIBERT, 2010, p. 15).

O trecho da matéria "O universo sexual da criança segundo Freud" conceitua as zonas erógenas como "partes da epiderme ou das mucosas onde o estímulo do prazer emite suas sensações" (PAIS \& FILHOS, mar. 1975, n. 7, p. 78). Trata-se de definição semelhante àquela apresentada em Três Ensaios sobre a Teoria da Sexualidade, de 1905, em que Freud afirmou que se trata de "uma parte da pele ou da mucosa em que certos tipos de estimulação provocam uma sensação prazerosa de determinada qualidade" (FREUD, 2006, p. 172).

A matéria de Pais \& Filhos fez referência direta às fases de desenvolvimento da organização sexual infantil estabelecidas por Freud e exemplifica um claro projeto de divulgação científica de saberes considerados canônicos no campo de conhecimentos acerca da infância.

Freud classificou as organizações sexuais pré-genitais em duas fases - oral ou canibalesca e sádico-anal (FREUD, 2006), considerando que nesse período as zonas genitais ainda não assumiram seu papel preponderante. Freud distingue a sexualidade da criança - auto-erótica, da adulta, na qual a obtenção de prazer fica a serviço da função reprodutora, e as pulsões parciais, sob o primado de uma única zona erógena, genital, formam uma organização sólida para a consecução do alvo sexual num objeto sexual alheio.

A matéria "A evolução sexual da criança", assinada por Lúcia Etienne Romeu, converge para uma direção semelhante à apresentada por Freud e considera de suma importância o conhecimento dos pais acerca do desenvolvimento sexual da criança:

Fala-se muito em fase oral, anal e genital no desenvolvimento da sexualidade de uma criança, mas a maioria dos pais não sabem do que se trata e o que isso significa no cotidiano de suas vidas com seus filhos. As dúvidas são muitas e os problemas que surgem, ligados ao sexo, são sempre difíceis de serem resolvidos. 0 que os pais precisam saber é que as crianças, desde que nascem, vão se preparando para a vida adulta, para a sexualidade plena. Embora não se possa negar uma sexualidade infantil, ela não é uma amostra grátis da vida adulta. Esta é consequência das experiências desde o nascimento [...] Assim, os pais devem procurar se informar sobre as fases do desenvolvimento da sexualidade, não reprimindo na criança o que é normal em cada faixa de idade. Um menino que se interessa pelos brinquedos da irmã, assim como uma menina que gosta de jogar bola com os meninos na rua, não estão tendo nenhum comportamento anormal. É preciso que os pais saibam que as crianças têm interesses múltiplos, que esses interesses variam de acordo com a idade e que a evolução sexual proporcionará a elas o pleno exercício da sexualidade adulta (REVISTA PAIS \& FILHOS, n. 1, set. 1975, p. 32). 
Infância nos caminhos da Psicologia: representações de infância psicologizada na revista Pais \& Filhos (19681989)

O trecho faz referência às fases de desenvolvimento da sexualidade da criança, respectivamente oral, anal e genital, e sinaliza que esta informação é, em grande medida, desconhecida pelos pais. Por outro lado, esse conhecimento é considerado importante, a fim de que os pais não reprimam um comportamento normal e esperado para a idade da criança. Cabe, ainda, ressaltar o argumento que estabelece uma diferenciação entre a sexualidade adulta e a infantil. A revista, nesta linha interpretativa, assume a tarefa educativa de levar às famílias conhecimentos psicanalíticos considerados relevantes pela equipe editorial e pelo grupo de consultores especializados. Veiculou-se, ainda, uma descrição mais detalhada em relação às fases oral e anal:

Desde bebê, começa a descobrir as partes do corpo e sente prazer com o ato de sugar e se amamentar. Aos dois anos, vive um período de transição, em que começa a perceber as diferenças sexuais. Ao atingir mais ou menos dois anos de idade, a criança começa a perceber as diferenças sexuais. É nessa idade que meninos e meninas descobrem suas características próprias e que seus órgãos sexuais são diferentes, surgindo, na menina, nessa fase, a inveja do órgão sexual masculino. Paralela à descoberta do próprio sexo, meninos e meninas sentem, nessa idade, o prazer em urinar e produzir fezes. É a chamada fase anal, que significa, para a criança, a satisfação em relação aos produtos do seu corpo. Mesmo que transmitam à criança que suas fezes são ruins, isso não deixa de lhe dar prazer (REVISTA PAIS \& FILHOS, n. 1, set. 1975, p. 33).

A consideração das fezes como material valioso produzido pelo corpo do próprio indivíduo consiste em apropriação da teoria freudiana, para quem as fezes podem representar gratificações, já que "ao desfazer-se dele, a criaturinha pode exprimir sua docilidade perante o meio que a cerca, e ao recusá-lo, sua obstinação" (FREUD, 2006, p. 176).

Em Pais \& Filhos, constatou-se a referência à fase anal em matérias pertinentes ao período de desfralde, ou nas palavras expressas em muitos artigos, a "fase do troninho". Em linhas gerais, há um discurso de apropriação da teoria freudiana que chamava a atenção dos pais para a especificidade e importância desse período no desenvolvimento da criança. 
Quem ignora o filho na fase do troninho poderá fugir das perguntas de sexo. E de nada adianta pretender que a criança adquira uma experiência inerente a uma etapa do seu desenvolvimento psicossexual, antes que ela tenha atingido esta etapa. Isto significa que a criança é uma organização em marcha, que se especializa através do tempo, desenvolvendo gradativamente formas adequadas de sobrevivência. Seu crescimento psicológico, como o físico, é geneticamente determinado, e cada etapa conquistada a seu tempo. Do nascimento à metade do segundo ano, aproximadamente, todas as gratificações e desejos infantis são primordialmente orais. A boca, os lábios e a língua atuam como órgãos proporcionadores de prazer, o que é facilmente constatado pela importância que representa para o bebê os atos de succionar e morder. Por volta de ano e meio, começa a fase anal, onde o outro extremo do aparelho digestivo se constitui no lugar mais importante de tensões e interesses. Agrado e desagrado são associados com expulsão e retenção das fezes e com as fezes em si. No terceiro ano, o interesse se volta para os órgãos genitais e amadurece até a idade adulta. Essas fases - oral, anal, fálica e genital - não são estanques. Uma sucede a outra em termos de dominância, sem que o predomínio de uma signifique o abandono das outras. E é na fase anal, quando o prazer se acha voltado para o controle dos esfíncteres, que a criança deve ser treinada para o uso do urinol (PAIS \& FILHOS, n. 5, jan. 1969, p. 16).

O artigo "O trono do reizinho", assinado por Laís Gama e Silva com a colaboração dos consultores José Francisco Gama e Silva, psicólogo clínico, e Dr. Jayme Vaisman, da equipe de pediatra de Pais \& Filhos, advoga uma representação de desenvolvimento infantil como "organização em marcha, cujo desenvolvimento ocorre de modo evolutivo e geneticamente determinado". O desenvolvimento psicossexual, desse modo, foi considerado como uma sucessão de fases, reforçando-se a dimensão etária desta etapa da vida.

Neste ponto, merece ser problematizado o enfoque biológico-evolucionista dado à questão, que remonta à origem das Ciências da Natureza e da Medicina e que atribuem à maturação uma importância preponderante. Freud, nesses termos, serve de exemplo do dito paradigma evolucionista, em que os atributos e as funções psicológicas são passíveis de mudanças conforme uma sequenciação hierarquizada, cuja maturação é considerada como juízo de valor (JOBIM E SILVA, 2007). A Psicanálise, motivada pelos trabalhos de Freud, contribuiu para a perspectiva biológica do comportamento que marcou as pesquisas no campo do Desenvolvimento Humano na virada do século XIX para o século XX (VASCONCELLOS, 2008).

$\mathrm{O}$ artigo também orienta os leitores a respeito do treinamento da criança para o uso do "troninho". Para tal, faz referência à obra do pediatra, psiquiatra e também psicanalista Donald W. Winnicott (1896-1971):

Lembro-me de um trecho do livro "A criança e a família”, do Dr. D. W. Winnicott, psicanalista inglês, que diz: "A palavra adestramento sempre me fez pensar em cuidado com os cachorros. 0 cachorro, porém, não precisa crescer até converter-se em um ser humano, de modo que quando nos referimos a um bebê, devemos partir do começo e o 
Infância nos caminhos da Psicologia: representações de infância psicologizada na revista Pais \& Filhos (19681989)

melhor é ver até que ponto podemos deixar de lado a palavra adestramento". Nenhuma pressão vinda de fora apresenta bons resultados, porque a criança se desenvolve de dentro para fora. A pediatria aponta a maturação progressiva do sistema nervoso como a determinante da ocasião ideal do controle dos esfíncteres. E esta maturação acontece em torno dos 18 meses. A explicação foi dada pelo pediatra (PAIS \& FILHOS, n. 5, jan. 1969, p. 17).

O discurso científico em torno da infância é valorizado em detrimento de práticas sociais correntes em relação ao desfralde, prevalecendo a maturação biológica como elemento relevante para o controle das necessidades fisiológicas. Importante também a afirmação de que o desenvolvimento da criança se dá de dentro para fora, demonstrando um discurso valorizador da dimensão individual do desenvolvimento.

No que diz respeito às investigações acerca do desenvolvimento psicossexual das crianças pequenas, além de Freud e Winnicott, outro nome de destaque no campo psicanalítico foi Melanie Klein (1882-1960). Pais \& Filhos compartilhou dessa afirmação ao considerá-la inovadora pela aplicação da Psicanálise em crianças em outra edição de "A criança e os grandes nomes da história":

\footnotetext{
Ela ousou discordar de Freud e, mesmo assim, foi respeitada na sua época. Melanie Klein dedicou 40 dos seus 78 anos de vida à psicanálise. Suas teorias, no início dessa ciência e do século, foram consideradas revolucionárias. Acima de tudo, seu nome está ligado às crianças porque mostrou ser possível a aplicação da teoria psicanalítica em pequenos pacientes. Mais do que contestar Freud, ela conseguiu acrescentar conhecimentos também para o tratamento de adultos. Até hoje, é reconhecida nos meios científicos e sua palavra, incluída entre a dos grandes mestres (REVISTA PAIS \& FILHOS, n. 12, ago. 1984, p. 27).
}

$\mathrm{O}$ artigo sugere que a aplicação da Psicanálise nas crianças, empreendida por Klein, foi relevante ponto de diferenciação em relação ao trabalho de S. Freud. Apesar de Freud dizer que a observação direta das crianças configurava fonte de investigação psicanalítica, suas investigações e teorias incidiram sobre o relato dos adultos e as lembranças inconscientes traduzidas em material consciente.

De acordo com as ideias veiculadas no texto, que apresentou um resumo da biografia de Melanie Klein, a inovação da psicanalista pautou-se na concepção de "infância como plena de impulsos agressivos e destrutivos, considerados por ela, ao Rev. Caminhos da Educação: diálogos, culturas e diversidades, Teresina, v. 2, n. 1, p. 106-126, jan./abr. 2020 
contrário de Freud, mais determinantes do que os impulsos sexuais" (REVISTA PAIS \& FILHOS, n. 12, ago. 1984, p. 30). Klein teria, então, identificado uma relação estreita entre as fases mais primitivas de desenvolvimento de uma criança e as perturbações psicóticas.

Também se discutiu a análise kleiniana na matéria assinada por Paulo Sternick "O que seu filho tem a ver com Melanie Klein", em que contou com as consultorias de Dr. Fábio Leite Lobo, diretor do Instituto de Psicanálise da Sociedade Psicanalítica do Rio de Janeiro, e de Maria Imelde Farah, psicanalista infantil e de adultos, da equipe de Pais \& Filhos. Comparando a abordagem de Klein com os estudos desenvolvidos por Freud, Paulo Sternick defendeu que

Melanie Klein teve o mérito de recuar a investigação psíquica, centrada no inconsciente, a períodos precoces da vida. Ela se dedicou à observação de crianças e bebês, e construiu, a partir dessas observações, um conjunto de ideias que se propõe a esclarecer o comportamento humano. Tentou mostrar as ocorrências psíquicas e os mecanismos mentais dos primeiros meses de vida e de que forma eles influem na personalidade infantil e adulta (REVISTA PAIS \& FILHOS, n. 1, set. 1971, p. 70).

Na matéria, citou-se o livro $A$ educação de crianças - à luz da investigação psicanalítica, organizado por Melanie Klein, Susan Isaacs e Ella Freeman Sharpe e lançado pela Editora Imago, do Rio de Janeiro, em 1969. Há referência, ainda, à obra $O$ Sentimento de Solidão - Nosso mundo adulto e outros ensaios, publicado pela mesma editora em 1971. Tal constatação permitiu verificar a atualidade da discussão empreendida por Pais \& Filhos no contexto social de produção de conhecimentos da Psicanálise sobre a infância.

O texto seguiu como uma espécie de resenha sobre as descobertas de Klein relacionadas aos primeiros meses de vida, segundo o qual o bebê viveria no mundo da fantasia inconsciente, permeado pelo não reconhecimento de si e pela angústia da dependência do outro. No terceiro e quarto meses, o bebê já conseguiria perceber a mãe como um todo, sentindo que poderia agredir, atacar e destruir o objeto amado. Para Klein, tratam-se "das primeiras emoções básicas, como a tristeza, o medo da perda e o sentimento de culpa" (REVISTA PAIS \& FILHOS, n. 1, set. 1971, p. 71).

Agregaram-se ao periódico informações a respeito do tratamento de Psicanálise infantil, nomeado como ludoterapia, aplicada com base na compreensão de que o jogo e a brincadeira são a linguagem infantil: "Através dela, o terapeuta, devidamente preparado na interpretação dos símbolos, descobre, além do conteúdo manifesto, o 
Infância nos caminhos da Psicologia: representações de infância psicologizada na revista Pais \& Filhos (19681989)

conteúdo latente do jogo e da brincadeira, da forma idêntica como um psicanalista interpreta os sonhos de seus pacientes adultos" (Ibid., p. 74).

Os articulistas de Pais \& Filhos valorizaram o conhecimento dos pais acerca dessas informações como estratégia de prevenção de muitos problemas, neuroses e sofrimentos. A compreensão da linguagem, motivação e símbolos expressos pelas crianças configuraram, portanto, uma das maiores lições que se poderia tirar da obra de Melanie Klein, opondo-se à valorização preponderante das expectativas, valores e modelos elucidados pelos pais.

No entanto, recomendou-se o tratamento psicanalítico no caso de crianças que apresentassem problemas de alimentação; de controle esfincteriano; demora na fala normal; criança que rói unhas; que demora a dormir e que tem pesadelos; teimosia ou dificuldades de aprendizado; criança que rouba coisas ou demonstra problemas de identificação (maneirismos ou feminilidade no filho ou pouca feminilidade na filha). Sendo assim, esse tipo de matéria possui um caráter educativo e também prescritivo, já que serve de exemplo do investimento científico em controlar terapeuticamente a família.

\section{Considerações finais}

As inúmeras matérias com alusões diretas às "fases de desenvolvimento da organização sexual infantil" estabelecidas por Freud, exemplificam um claro projeto de divulgação científica de saberes considerados canônicos no campo de conhecimentos acerca da infância. A esse respeito, mereceu ressalva o enfoque biológico-evolucionista dado à temática do desfralde, que remontou à origem das Ciências da Natureza e da Medicina e que atribuem à maturação um lugar preponderante.

A Psicanálise, mobilizada pelos trabalhos de Freud, contribuiu para a perspectiva biológica do comportamento que marcou as pesquisas no campo do Desenvolvimento Humano na virada do século XIX para o século XX. Tratava-se de 
uma abordagem que afirmava que os atributos e funções psicológicas são passíveis de certas mudanças, limitadas por uma sequenciação hierarquizada.

Ao final da investigação, verificou-se que a revista Pais \& Filhos atuou como espaço pedagógico de formação dos pais-leitores, na medida em que serviu de guia aparentemente confiável e especializado para a explicação dos comportamentos infantis e espaço de divulgação de recomendações de modos de ser e agir. Não se pode negar, pois, que os enunciados veiculados no periódico forneceram indícios das estratégias discursivas em circulação em nossa sociedade, voltadas para a constituição de corpos infantis, deixando clara a dimensão cultural da constituição identitária.

Espera-se, assim, que este estudo contribua para o campo de produção científica que tem as representações relativas à infância e à sua educação como foco, assim como para o campo de estudos da História da Educação que tem a imprensa periódica de ampla circulação como fonte privilegiada de pesquisa.

\section{Referências:}

ANTUNES, Mitsuko Aparecida Makino. A psicologia no Brasil: leitura histórica sobre sua constituição. 5. ed. - São Paulo: EDUC, 2014.

CAMBI, Franco. História da Pedagogia. Tradução de Álvaro Lorencini. São Paulo: Fundação Editora UNESP (FEU), 2009.

CHARTIER, Roger. O mundo como representação. In: CHARTIER, Roger. À beira da falésia: a história entre certezas e inquietude. Porto Alegre: Ed. UFRGS, 2002.

DEL PRIORE, Mary (Org.). História das Crianças no Brasil. São Paulo: Contexto, 1999.

FOUCAULT, Michel. História da Sexualidade I. Tradução de Maria Thereza da Costa Albuquerque. Rio de Janeiro: Edições Graal, 19a edição, 2009.

FOUCAULT, Michel. Os anormais. São Paulo: Martins Fontes, 2001.

FREUD, Sigmund. Obras psicológicas completas de Sigmund Freud. Vol. VII. Edição Standard brasileira. Traduzido do alemão e do inglês sob a direção geral de Jayme Salomão. Rio de Janeiro: Imago, 2006.

JOBIM E SILVA, Solange. Re-significando a psicologia do desenvolvimento: uma contribuição crítica à pesquisa da infância In: KRAMER, Sonia e LEITE, Maria Isabel. Infância: fios e desafios da pesquisa. 9. ed. Campinas, SP: Papirus, 2007. 
Infância nos caminhos da Psicologia: representações de infância psicologizada na revista Pais \& Filhos (19681989)

JOLIBERT, Bernard. Sigmund Freud. Tradução: Elaine Teresinha Dias. Recife: Fundação Joaquim Nabuco, Editora Massangana, 2010.

KUHLMANN JR., Moysés; FERNANDES, Rogério. Sobre a história da infância. In: FARIA FILHO, Luciano Mendes (Org.). A infância e sua educação: materiais, práticas e representações (Portugal e Brasil). Belo Horizonte: Autêntica, 2004, p. 15-33.

NÓVOA, António. A imprensa de Educação e Ensino: concepção e organização do repertório português. IN: CATANI, Denice Barbara; BASTOS, Maria Helena Camara (Orgs.) Educação em revista: a imprensa pedagógica e a história da educação. São Paulo: Escrituras Editora, 2002.

PEREIRA, Rita Marisa Ribes. Tudo ao mesmo tempo agora: considerações sobre a infância no presente. In: In: GONDRA, José Gonçalves. (Org.) História, Infância e Escolarização. 1. ed. Rio de Janeiro: 7Letras, 2002, p. 152-167.

REVISTA PAIS \& FILHOS. Rio de Janeiro: Bloch Editores, ano 1, n. 5, jan. 1969, 132 $\mathrm{p}$

. Rio de Janeiro: Bloch Editores, ano 4, n. 1, set. 1971, 148 p.

. Rio de Janeiro: Bloch Editores, ano 5, n. 5, jan. 1973, 100 p.

. Rio de Janeiro: Bloch Editores, ano 7, n. 7, mar. 1975, 116 p.

. Rio de Janeiro: Bloch Editores, ano 8, n. 1, set. 1975, 116 p.

. Rio de Janeiro: Bloch Editores, ano 13, n. 12, ago. 1981, 124 p.

. Rio de Janeiro: Bloch Editores, ano 16, n. 9, maio 1984, 124 p.

. Rio de Janeiro: Bloch Editores, ano 16, n. 12, ago. 1984, 124 p.

. Rio de Janeiro: Bloch Editores, ano 18, n. 4, dez. 1985, 124 p.

RAPPAPORT, Clara Regina; FIORI, Wagner Rocha; DAVIS, Cláudia. Psicologia do desenvolvimento. Volume 1: conceitos fundamentais. São Paulo: Ed. EPU, 1981.

ROGOFF, Barbara. A natureza cultural do desenvolvimento humano. Tradução Roberto Cataldo Costa. Porto Alegre: Armed, 2005. 
SANTOS, Liana Pereira Borba dos Santos. Infância e família em revista: Pais \& Filhos (1968-1989). Tese (Doutorado em Educação), Universidade do Estado do Rio de Janeiro, Rio de Janeiro, 2018.

SANTOS, Liana Pereira Borba dos. "Mais que uma revista, um dicionário para os pais": a revista Pais \& Filhos e a imprensa transnacional para a família. Revista Brasileira de História da Educação, 19. DOI: http://dx.doi.org/10.4025/rbhe.v19.2019.e079

VASCONCELLOS, Vera Maria Ramos de. Infância e Psicologia: Marcos teóricos da compreensão do desenvolvimento da criança pequena. In: SARMENTO, Manuel, GOUVEA, Maria Cristina Soares de (Orgs). Estudos da infância: educação e práticas sociais. Petrópolis, RJ: Vozes, 2008, p. 62-81. 